\title{
Individual drug counselling plus group drug counselling was effective in patients with cocaine dependence
}

\author{
Crits-Christoph P, Siqueland L, Blaine J, et al. Psychosocial treatments for cocaine dependence: National Institute on Drug \\ Abuse Collaborative Cocaine Treatment Study. Arch Gen Psychiatry 1999 Jun;56:493-502.
}

\author{
QUESTION: In patients with cocaine dependence, how effective are psychosocial \\ treatments?
}

\section{Design}

Randomised (allocation concealed*), blinded \{outcome assessors $\}^{* \dagger}$, controlled trial with 12 months of follow up.

\section{Setting}

5 university and hospital sites in the US.

\section{Patients}

487 patients between 18 and 60 years of age (mean age $34 \mathrm{y}, 77 \%$ men) with a principal diagnosis of DSM-IV cocaine dependence and who had used cocaine in the previous 30 days. Exclusion criteria included unstable living arrangements, opioid or polysubstance dependence, dementia, psychotic symptoms, unstable medical illness, and suicide or homicide risk. $83 \%$ of patients completed the 9 or 12 month follow up assessment.

\section{Intervention}

Patients were allocated to 1 of 4 manual guided treatments: (1) individual drug counselling plus group drug counselling (IDC + GDC) $(\mathrm{n}=121)$; (2) cognitive therapy plus GDC (CT + GDC) $(\mathrm{n}=119)$; (3) supportive expressive therapy plus GDC (SE + GDC) $(n=124)$; or (4) GDC alone ( $n=123)$. Treatment lasted for 6 months.

\section{Main outcome measures}

Primary outcome measures were change in the Addiction Severity Index-Drug Use Composite score and the number of days of cocaine use in the previous month.

\section{Main results}

The analysis was by intention to treat. Patients assigned to IDC + GDC showed the greatest improvement on the Addiction Severity Index-Drug Use Composite score compared with those assigned to the 2 psychotherapies $(p=0.006)$ or to GDC alone $(p=0.009)$. IDC + GDC was also superior to the 2 psychotherapies on

Percentage of patients who achieved 3 months of consecutive abstinence from cocaine use $\$$

\begin{tabular}{|c|c|c|c|}
\hline IDC + GDC & $\begin{array}{l}\text { CT + GDC } \\
\text { SE + GDC } \\
\text { GDC alone }\end{array}$ & RBI $(95 \% \mathrm{CI})$ & NNT (Cl) \\
\hline $38 \%$ & $23 \%$ & $\begin{array}{l}68 \% \\
(13 \text { to } 151)\end{array}$ & $\begin{array}{l}7 \\
\text { (4 to } 27 \text { ) }\end{array}$ \\
\hline $38 \%$ & $18 \%$ & $\begin{array}{l}114 \% \\
\text { (39 to 234) }\end{array}$ & $\begin{array}{l}5 \\
\text { (4 to } 11)\end{array}$ \\
\hline $38 \%$ & $27 \%$ & $\begin{array}{l}41 \% \\
(-2 \text { to } 106)\end{array}$ & Not significant \\
\hline
\end{tabular}

fIDC=individual drug counselling; $\mathrm{GDC}=$ group drug counselling; $\mathrm{CT}=$ cognitive therapy; $\mathrm{SE}=$ supportive expressive therapy. Other abbreviations defined in glossary; RBI, NNT, and $\mathrm{Cl}$ calculated from data in article. the number of days of cocaine use in the previous month $(\mathrm{p}=0.002)$. More patients assigned to IDC + GDC achieved and maintained abstinence (table).

\section{Conclusion}

Individual drug counselling plus group drug counselling was effective in patients with cocaine dependence.

*See glossary.

$\dagger$ Information provided by the author.

\section{COMMENTARY}

The Collaborative Cocaine Treatment Study (CCTS) is well designed and has implications for matching patients to different psychosocial treatments.

The CCTS results of differential effectiveness of one psychosocial treatment in cocaine dependency are in contrast with findings of other recent trials which found either no differences among psychosocial treatments ${ }^{1-3}$ or differential effectiveness for cognitive behavioural treatment. ${ }^{4}$ The heterogeneous results are consistent with clinically distinct subgroups of cocaine dependent patients who respond to specialised treatment methods. ${ }^{145}$ The problem that clinicians now face is the defining characteristics for the different subgroups have not been firmly established. In addition, the patient matching results from the methadone maintenance studies do not generalise to cocaine dependency.

The manual based group and individual abstinence oriented drug counselling used in the CCTS could be expected to provide effective treatment for a limited number of cocaine dependent patients that fit the study's exclusion criteria. Other clinically relevant exclusions that were not noted in the abstract are bipolar I disorder, legally mandated treatment, pending incarceration, and use of psychotropic medication.

James Westphal, MD

Louisiana State University Medical Center Shreveport, Louisiana, USA

1 Carrol KM, Rounsaville BJ, Gordon LT, et al. Psychotherapy and pharmacotherapy for ambulatory cocaine abusers. Arch Gen Psychiatry 1994;51:177-87.

2 Gottheil E, Weinstein SP, Sterling RC, et al. A randomized controlled study of the effectiveness of intensive outpatient treatment for cocaine dependence. Psychiatr Serv 1998;49:782-7.

3 Higgins S, Budney AJ, Bickel WK, et al. Outpatient behavioral treatment for cocaine dependence: one-year outcome. In Marlatt GA, Van den Bos GR, editors. Addictive behaviors: readings on etiology, prevention, and treatment. Washington DC: American Psychological Association, 1997.

4 Maude-Griffin PM, Hohenstein JM, Humfleet GL, et al. Superior efficacy of cognitive-behavioral therapy for urban crack cocaine abusers: main and matching effects. J Consult Clin Psychol 1998;66:832-7.

5 Thornton CC, Gottheil E, Weinstein SP, et al. Patienttreatment matching in substance abuse. Drug addiction severity.J Subst Abuse Treat 1998;15:505-11.
Source of funding: National Institute on Drug Abuse.

For correspondence: Dr P Crits-Christoph, Department of Psychiatry, University of Pennsylvania, 3600 Market Street, Room 700, Philadelphia, PA 19104, USA.Fax +1 2153495171. 